\title{
A EDUCAÇÃO A DISTÂNCIA E A DISTÂNCIA dA EDUCAÇÃO: APONTAMENTOS PARA O DEBATE SOBRE EXERCícIO E FORMAÇÃo PROfISSIONAL EM SERVIÇO SOCIAL
}

\section{EDUCATION IN THE DISTANCE AND DISTANCE OF EDUCATION: NOTES TO THE DEBATE ON WORK AND VOCATIONAL TRAINING IN SOCIAL WORK}

Juliana Iglesias Melim ${ }^{1}$

\section{RESUMO}

O presente artigo problematiza sobre a relação entre trabalho e formação profissional dos assistentes sociais na contemporaneidade. Para tal, sinaliza os processos de precarização que atingem essas duas dimensões e aborda a expansão da graduação a distância em Serviço Social como expoente máximo da precarização na formação profissional.

PALAVRAS-CHAVE: Serviço Social. Formação Profissional. Educação a Distância.

\begin{abstract}
This article discusses the relationship between work and professional training of social workers in contemporary times. To do so, it signals the processes of precariousness that reach these two dimensions and addresses the expansion of distance graduation in Social Work as the greatest exponent of the precariousness in vocational training.
\end{abstract}

KEYWORDS: Social Work. Education. Distance Education.

\footnotetext{
${ }^{1}$ Assistente Social, docente do Departamento de Serviço Social da Universidade Federal do Espírito Santo, Conselheira do Conselho Federal de Serviço Social gestões 2011-2014 e 2014-2017. Doutoranda em Serviço Social pelo Programa de Pós-Graduação em Serviço Social da Universidade Federal do Rio de Janeiro (UFRJ). E-mail: juliana_melim@yahoo.com.br. Telefone: 27 99893.4786.
} 


\section{INTRODUÇÃO}

O exercício e a formação profissional do assistente social tem sido tema presente na agenda da categoria, mas que ainda necessita ganhar maior centralidade na produção teórica acadêmica de profissionais, estudantes e pesquisadores do Serviço Social brasileiro $^{2}$. Esse elemento indica a relevância do aprofundamento de estudos e pesquisas que decifrem o movimento e as contradições dos processos pelos quais a profissão particulariza as expressões das leis tendenciais do capitalismo num dado momento histórico.

No presente artigo pretendemos analisar a expansão do ensino de graduação a distância em Serviço Social nos marcos das transformações societárias do capitalismo contemporâneo, e nesse caminho algumas perguntas se colocam de imediato: Por que a expansão da graduação a distância em Serviço Social neste momento histórico? Como tem ocorrido essa expansão? Há relação entre a expansão da formação profissional e o mercado de trabalho? Qual perfil e quais as requisições são demandadas para o assistente social no atual estágio de desenvolvimento do capitalismo e como a formação profissional é atravessada e atravessa essas questões?

Dentre as argumentações e respostas possíveis a esses questionamentos, pretendemos esquadrinhar dois campos intimamente interligados, indicando o que nos parece ser interessante explicitar: de um lado, uma frente ainda pouco explorada do estudo aprofundado sobre a expansão do ensino de graduação a distância em Serviço Social, lançando luzes sobre o perfil profissional que vai se gestando no contexto de crise estrutural do capital, de contrarreforma do Estado brasileiro e novas configurações da política social; de outro lado, aquela constituída pelo esforço interpretativo de compreender as atuais condições e requisições postas ao exercício profissional dos assistentes sociais brasileiros.

\footnotetext{
${ }^{2}$ Em levantamento realizado pelo Grupo Temático de Pesquisa (GTP) “Serviço Social, Fundamentos, Formação e Trabalho Profissional” da Associação Brasileira de Ensino e Pesquisa em Serviço Social (ABEPSS) observa-se baixa produção teórica sobre os temas "trabalho e formação profissional em Serviço Social”. Dados do Banco de Dissertações e Teses da Coordenação de Aperfeiçoamento de Pessoal de Nível Superior (CAPES) indicam que entre os anos de 2000 e 2010 foram produzidas apenas 9 (nove) teses que discorriam sobre o exercício profissional do assistente social e 7 (sete) sobre a formação profissional nessa área (ABEPSS, 2012).

Serv. Soc. \& Saúde, Campinas, SP v. 14, n. 2 (20), p. 155-178, jul./dez. 2015 ISSN 1676-6806
} 
Sabemos que as transformações na dinâmica do capitalismo afetam sobremaneira o mundo do trabalho, seus processos e sujeitos, além de provocarem redefinições profundas no papel do Estado e nas políticas sociais, exigindo novos perfis de trabalhadores, novas requisições e demandas ao mundo do trabalho, e particularmente, novos perfis, requisições e demandas para o exercício e a formação profissional do assistente social.

Partimos da premissa de que existe uma relação dialética entre trabalho e educação ${ }^{3}$, sendo o trabalho a categoria determinante nesse processo. Ou seja, para nossas análises as mudanças no mundo do trabalho tencionarão as mudanças no campo da política de educação superior e, consequentemente, na formação profissional. Nesse caminho, se a relação é dialética, faz-se necessário considerarmos também que, uma vez que a formação profissional contribui para configuração de um determinado perfil de profissional, este também irá incidir no exercício da profissão. Logo, uma análise crítica e profunda da formação profissional em Serviço Social não pode ser dissociada de uma densa análise do trabalho e do trabalho do assistente social nos marcos do capitalismo contemporâneo.

Compreende-se que a reflexão teórica sobre estas questões nos exige apreender diversas dimensões da realidade concreta, como: o perfil de trabalhador que vem se gestando tendo em vista atender às necessidades do capital de se valorizar; o perfil de assistentes sociais que vem se formando para este mesmo fim; as configurações da política social, reconhecida aqui como base de sustentação funcional-ocupacional do Serviço Social; as características do ensino superior e as contradições que se colocam para a formação profissional em Serviço Social; a descoberta do curso de Serviço Social como nicho de valorização e sua relação com a demanda de mercado, considerando o formato que adquire o enfrentamento das expressões da questão social pelo Estado e as classes na contemporaneidade; além da apreensão dos movimentos de luta e resistência da classe trabalhadora e, particularmente, da categoria profissional dos assistentes sociais. Nessa direção, os caminhos e descaminhos do exercício e da formação

\footnotetext{
${ }^{3}$ Defendemos aqui uma concepção de educação como princípio formativo. Segundo Horodynski (2009), a educação é mais ampla que ensino e não é equivalente de atividades didáticas. Educação prepara para a vida em sociedade; promove saberes socialmente referenciados, ou seja, saberes que vão ao encontro das demandas, valores e necessidades da população. É formação. Dessa forma, educação e formação andarão juntas. Formação profissional é um processo permanente de qualificação e atualização, porque exige o deciframento cotidiano da realidade social.
}

Serv. Soc. \& Saúde, Campinas, SP v.15, n. 2 (22), p. 155-178, jul./dez. 2016 ISSN 1676-6806 
profissional dos assistentes sociais só podem ser analisados em sua densidade histórica tendo como suporte o palco da ordem capitalista e da luta de classes.

Buscaremos assim como Brás Cubas ${ }^{4}$ fixar o relâmpago para melhor captar a lógica constitutiva dos processos históricos de forma mais aprofundada. Como a conjuntura atual não hegemoniza forças de ruptura com a ordem vigente - o sistema capitalista - o debate sobre exercício e formação profissional dos assistentes sociais não pode abstrair as condições concretas desse sistema. Assim, a direção teórica que orienta nossos estudos se fundamenta na impossibilidade de separação da leitura e análise do exercício e da formação profissional em Serviço Social da reflexão mais profunda das relações sociais de produção capitalista.

\section{OS FUNDAMENTOS DO TRABALHO DO ASSISTENTE SOCIAL NA CONTEMPORANEIDADE}

O ponto de partida para a análise do Serviço Social é o de que a profissão é um produto histórico, tanto indissociável das particularidades assumidas pela formação e desenvolvimento da sociedade brasileira no âmbito da economia mundial e da divisão internacional do trabalho, quanto resultante da ação dos sujeitos sociais que desenham sua trajetória e redirecionam seus rumos (IAMAMOTO, 2012).

Compreende-se que o Serviço Social consiste em uma profissão que se inscreveu na divisão social e técnica do trabalho em um determinado momento histórico do capitalismo, mais especificamente em sua fase conhecida como monopolista, para responder necessidades e interesses que garantissem a reprodução social da ordem vigente. Assim, considerando a historicidade da profissão, podemos afirmar que ela se configura e se recria no âmbito das relações entre o Estado e a sociedade, resultado de determinantes macrossociais que estabelecem limites e possibilidades ao exercício profissional.

\footnotetext{
${ }^{4}$ Personagem de Machado de Assis no romance “Memórias Póstumas de Brás Cubas” que morre e, ato contínuo, se levanta da tumba para, diante do leitor, se tornar autor de suas memórias. Narra que a história do homem e da terra é tão intensa que para descrevê-la seria preciso fixar o relâmpago.

Serv. Soc. \& Saúde, Campinas, SP v. 14, n. 2 (20), p. 155-178, jul./dez. 2015 ISSN 1676-6806
} 
Dessa maneira, a profissão somente pode ser compreendida a partir do lugar que ocupa na divisão social e técnica do trabalho, cujo espaço sócio ocupacional é dado pelas políticas sociais ${ }^{5}$. No entanto, é necessário destacar que toda profissão é, também resultado da ação dos sujeitos individuais e coletivos que atuam no interior da mesma.

A partir dessa perspectiva, as reflexões sobre a formação e o trabalho do assistente social na atualidade exigem que voltemos à atenção para o atual momento histórico, observando as mudanças no padrão de acumulação e regulação social, nos marcos da mundialização e financeirização do capital, e a maneira como estes processos incidem no Brasil diante de sua inserção dependente na economia mundial. Sabe-se que este movimento vem provocando profundas mudanças na produção de bens e serviços, nas formas de organização e gestão do trabalho e na forma como os direitos sociais vêm sendo (ou não) garantidos.

Os anos de 1980 foi uma década de grande avanço tecnológico, a automação, a robótica e a microeletrônica dominaram o universo fabril, inserindo-se e desenvolvendo-se nas relações de trabalho e de produção do capital. O toyotismo penetrou, combinando-se ou mesmo substituindo o padrão fordista dominante, em várias partes do capitalismo globalizado. Passamos a vivenciar novas formas de produção, cujos desdobramentos foram e ainda são também agudos, no que se refere aos direitos do trabalho. Estes passam a ser desregulamentados e flexibilizados, de modo a dotar o capital do instrumental necessário para adequar-se a sua nova fase (ANTUNES, 2006; BEHRING, 2009). Direitos e conquistas históricas dos trabalhadores foram substituídos e eliminados do mundo da produção. Diminuiu-se ou mesclaram-se, dependendo da intensidade, o despotismo taylorista, pela participação dentro da ordem e do universo da empresa, pelo envolvimento manipulatório, próprio da sociabilidade moldada contemporaneamente pelo sistema produtor de mercadorias (ANTUNES, 2006).

Neste contexto, a acumulação flexível se consolida enquanto forma de organização da produção no capitalismo contemporâneo marcando um confronto direto

\footnotetext{
${ }^{5}$ Compreendemos no presente trabalho a política social como processo e resultado de relações contraditórias e complexas que se originam na relação entre Estado e sociedade, no interior da luta de classes, atravessando e sendo atravessadas pelo movimento de produção e reprodução do modo de produção capitalista. Assim, as políticas sociais não podem ser tratadas como produtos fixos, como algo independente da história.

Serv. Soc. \& Saúde, Campinas, SP v.15, n. 2 (22), p. 155-178, jul./dez. 2016 ISSN 1676-6806
} 
com a rigidez do fordismo. Ela se sustenta na flexibilidade dos processos de trabalho, dos mercados de trabalho, dos produtos e padrões de consumo. Possibilita o surgimento de setores de produção inteiramente novos, novas maneiras de fornecimento de serviços financeiros, novos mercados e, sobretudo, taxas altamente intensificadas de inovação comercial, tecnológica e organizacional. A acumulação flexível apresenta rápidas mudanças dos padrões do desenvolvimento desigual, tanto entre setores como entre regiões geográficas, criando, por exemplo, um vasto movimento do emprego no chamado 'setor de serviços', bem como conjuntos industriais completamente novos em regiões até então localizadas na periferia da economia mundial (HARVEY, 1992).

A introdução das novas tecnologias geraram excedentes de força de trabalho, que tornaram o retorno de estratégias absolutas de mais-valia, mais viável mesmo nos países capitalistas avançados. A superexploração, do trabalho em casa, bem como o enorme crescimento das práticas de trabalho no setor informal por todo o mundo capitalista, representa o ataque ao trabalho com direitos (ANTUNES, 2006; BEHRING, 2009). É possível observar ainda altos índices de desemprego estrutural e retrocesso na ação sindical, ou seja, toda essa processualidade própria da dinâmica de valorização do capital garantiu as condições sociais favoráveis para a deteriorização das condições de trabalho e de vida da classe trabalhadora, o individualismo exacerbado e a competitividade.

Essas transformações, presentes ou em curso, em maior ou menor escala, dependendo de inúmeras condições econômicas, sociais, políticas, culturais, etc..., dos diversos países onde são vivenciadas, afetam diretamente a classe trabalhadora, acarretando fortes mudanças no ser do trabalho (ANTUNES, 2006).

Assim, para atender às exigências do mercado um novo perfil de trabalhador vai se gestando. É necessário que a produção se sustente num processo produtivo flexível, que permita ao trabalhador executar várias atividades ao mesmo tempo. É a chamada polivalência do trabalhador, que favorece a desespecialização e valoriza a figura do trabalhador multifuncional (ANTUNES, 2006; BEHRING, 2009).

Ou seja, os novos valores propagados pelo mundo do capital não envolvem apenas a esfera da produção e os operários fabris. Todas essas metamorfoses envolvem, de modo mediato, o conjunto das relações sociais, incluindo, dentre outras Serv. Soc. \& Saúde, Campinas, SP v. 14, n. 2 (20), p. 155-178, jul./dez. 2015 ISSN 1676-6806 
especializações do trabalho coletivo, o Serviço Social, visto que a profissão acompanha este movimento e dele recebe influências, ou seja, a profissão particulariza os determinantes histórico-universais.

Esse tempo histórico que engendrou profundas mudanças na dinâmica do capitalismo e também no mundo do trabalho, marcou, contraditoriamente, relevantes contornos na direção social, política e teórica do Serviço Social brasileiro.

As bases do atual Projeto Ético Político profissional ${ }^{6}$ que marca o reconhecimento de classe e o compromisso com os interesses dos trabalhadores foram sendo solidificadas ainda nos anos 1970/1980 e ganham força nos anos 1990. É certo pensarmos que o processo de "virada” do Serviço Social brasileiro - sua ruptura teórica e política com o conservadorismo de suas origens - se consolida numa conjuntura extremamente adversa para a classe trabalhadora e desde então a profissão passa, de forma hegemônica, a "remar contra a maré”. Todo esse movimento é impulsionado pela intensificação das lutas sociais contra o regime militar no Brasil e pela possibilidade de transição democrática que tais lutas iam acumulando. Dessa forma, a "virada” dos rumos da profissão perpassa o acúmulo das lutas pela conquista do Estado de Direito e do processo de democratização da vida social que envolvem tanto o Estado quanto a sociedade, lutas essas lideradas pelo movimento das classes trabalhadoras sob direção do operariado industrial, que compreende a economia, a política e a cultura.

Encontra-se aí o alicerce sociopolítico que tornou socialmente possível e viável o deslocamento das interpretações de cunho estrutural-funcionalista da cena principal do debate profissional, alargando espaços para vertentes histórico-críticas no universo do Serviço Social (IAMAMOTO, 2007, p. 212).

Nessa trilha o amadurecimento teórico e ético-político da profissão avança em solo não tão fértil que conforme já assinalado expressam grandes mudanças no padrão de acumulação e regulação social. Os últimos trinta anos que marcam avanços na categoria profissional marcam também recorrentes processos de empobrecimento material e espiritual da classe trabalhadora.

\footnotetext{
${ }^{6}$ Concordamos com Netto (1995, p. 95) que os projetos profissionais “[...] apresentam a autoimagem da profissão, elegem valores que a legitimam socialmente, delimitam e priorizam seus objetivos e funções, formulam requisitos (técnicos, institucionais e práticos) para o seu exercício, prescrevem normas para o comportamento dos profissionais e estabelecem balizas de sua relação com os usuários dos seus serviços, com outras profissões e com as organizações e instituições, públicas e privadas”. Concordamos ainda que os projetos profissionais, sobretudo o projeto do Serviço Social brasileiro, se relacionam a projetos societários que imprimem certas matrizes e valores.
}

Serv. Soc. \& Saúde, Campinas, SP v.15, n. 2 (22), p. 155-178, jul./dez. 2016 ISSN 1676-6806 
Os processos de financeirização e mundialização do capital, combinados com o projeto neoliberal provocam intensas modificações na produção das mercadorias (bens e serviços), no perfil do trabalhador, na organização e na gestão do trabalho no interior da produção. Destacamos ainda que esses processos são permeados e permeia a contrarreforma do Estado que se sustenta nas privatizações, no afastamento da intervenção estatal nas respostas às demandas sociais, no desmonte e na regressão dos direitos trabalhistas e sociais provocando o acirramento das expressões da questão social, o que atingirá duplamente os assistentes sociais: pela sua condição de trabalhador assalariado que atua, majoritariamente, no campo das políticas sociais e pelo seu atendimento à população usuária, classe trabalhadora empobrecida que cada vez mais apresenta suas demandas sociais nos serviços sociais, especialmente públicos.

A entrada em cena desses elementos tensiona a profissão, suas finalidades e atribuições. Atravessa o exercício e a formação profissional em Serviço Social, visto que os espaços de trabalho e também da formação, enquanto resultados dos processos históricos, sofrem significativas alterações.

Elas são indissociáveis dos processos de reestruturação produtiva e gerencial das empresas e do aparelho de Estado, da intensificação e desregulamentação do trabalho, das investidas contra a organização dos trabalhadores (IAMAMOTO, 2007, p. 231-232).

Assim, essas alterações provocam, sobretudo, a perda de direitos e liberdades democráticas e se associam à reorganização do Estado segundo as diretrizes neoliberais.

Em que se pese a inserção periférica e dependente do Brasil no capitalismo mundial, sabemos que no Brasil, como em outros países da América Latina não vivemos a experiência de constituição de um Estado de Bem Estar Social, de forma que os direitos sociais por aqui nunca foram efetivados. "Dada essa particularidade, diferentemente dos países capitalistas centrais, nos países periféricos, especialmente no Brasil, não há ‘gorduras’ para cortar” (GUERRA, 2010, p. 91).

Significa que nos processos de reação burguesa à crise de 1970 a dinâmica da contrarreforma do Estado, iniciada no Brasil a partir dos anos 1990, concretiza e reatualiza as cenas das desigualdades e dependência da nossa formação social, recolocando as históricas mediações constitutivas do capitalismo tupiniquim antidemocrático e excludente. A instabilidade dos direitos duramente conquistados Serv. Soc. \& Saúde, Campinas, SP v. 14, n. 2 (20), p. 155-178, jul./dez. 2015 ISSN 1676-6806 
revela, em grande medida, a subordinação brasileira aos organismos internacionais negando ou violando direitos sociais que poderiam ser materializados através da execução de políticas sociais. “Altera-se a função precípua das políticas sociais, que é a de controlar a fúria do capital e do mercado, a qual Netto [1998] denomina de 'função democrático-reguladora’ em face do mercado” (GUERRA, 2010, p. 93).

[...] no que diz respeito aos programas sociais, [temos o] trinômio articulado da focalização, privatização e descentralização. Assim, trata-se de desuniversalizar e assistencializar as ações. Uma política social residual que soluciona apenas o que não pode ser enfrentado pela via do mercado, da comunidade e da família. O carro-chefe dessa proposição é a renda mínima, combinada à solidariedade por meio das organizações da sociedade civil (BEHRING, 2009, p. 310).

A hegemonia neoliberal que se consolida no país dilui a dimensão de conquista das políticas sociais e as reduzem à sua funcionalidade à acumulação capitalista, recuperando o velho padrão enquanto concessão do Estado.

Pode-se dizer ainda que existe uma relação direta entre precarização e diversas formas de flexibilização do trabalho e dos direitos. A precarização do trabalho e a flexibilização dos direitos são as mudanças mais visíveis de um período de hegemonia do capital financeiro e de enfraquecimento da organização da classe trabalhadora. Relacionada a esta engrenagem está também o enfrentamento da chamada questão social com pobres políticas para pobres, políticas focalizadas e voltadas para a redução da pobreza absoluta (GUERRA, 2011).

Ora, esse contexto altera a demanda de trabalho do Assistente Social, modifica o mercado de trabalho, altera os processos de trabalho e as condições em que se realizam, nos quais assistentes sociais ingressam enquanto profissionais assalariados. As relações de trabalho tendem a ser desregulamentadas e flexibilizadas. Verifica-se uma ampla retração dos recursos institucionais para acionar a defesa dos direitos e dos rateios de acessá-los. Enfim, tem-se um redimensionamento das condições do nosso exercício profissional, porque ele se efetiva pela mediação das condições do assalariamento (IAMAMOTO, 2012, p. 40).

Com isso os assistentes sociais também sofrem os efeitos da intensificação do trabalho, da polivalência, da redução dos programas sociais e benefícios, da focalização desses programas, das exigências de requalificação da força de trabalho, da desregulamentação, da desprofissionalização e da competitividade. 
Neste debate sobre o trabalho profissional ainda podemos destacar a ampliação dos cargos genéricos, que contribui para a diluição das particularidades profissionais; o envolvimento de assistentes sociais, no exercício profissional, em atividades alheias à sua formação e às competências e atribuições privativas expressas na Lei que Regulamenta a Profissão (Lei 8.662/1993), a negação das atribuições privativas profissionais em nome do suposto trabalho multidisciplinar e o crescimento da prática do trabalho voluntário, reconhecido e estimulado em todos os países pelos organismos internacionais e governos nacionais e que tem sido reconhecido no meio profissional como quesito para "adensar" o currículo, especialmente dos assistentes sociais recémformados que ainda não possuem experiência profissional.

São exemplos desses processos a regulamentação por parte do Conselho Federal de Serviço Social da Resolução CFESS n 572/2010 que dispõe sobre a obrigatoriedade de registro nos Conselhos Regionais de Serviço Social, dos assistentes sociais que exerçam funções ou atividades de atribuição do assistente social, mesmo que contratados sob a nomenclatura de cargos genéricos; a Resolução CFESS nº 569/2010 que veda a realização de terapias associadas ao título e/ou ao exercício profissional do assistente social; a Resolução CFESS n ${ }^{0}$ 557/2009 que discorre sobre a emissão de pareceres, laudos, opiniões técnicas conjuntos entre o assistente social e outros profissionais, bem como a Resolução CFESS n 554/2009 - atualmente suspensa por decisão da $1^{\mathrm{a}}$ Vara Federal da Seção Judiciária do Ceará - mas, que dispõe sobre o não reconhecimento da inquirição das vítimas crianças e adolescentes no processo judicial, sob a Metodologia do Depoimento Sem Dano/DSD, como sendo atribuição ou competência do profissional assistente social.

Também as pesquisas realizadas sobre o perfil e as condições de trabalho dos assistentes sociais brasileiros ainda que insuficientes para um quadro mais geral $^{7}$ indicam tendências que merecem a atenção da categoria: desemprego, contratos temporários e parciais, baixos salários, com pouco acesso aos programas de pósgraduação e grandes fragilidades no processo de formação profissional e conhecimento das normativas que disciplinam a profissão. "Essas tendências reforçam a inserção

\footnotetext{
${ }^{7}$ Iremos nos remeter especialmente a pesquisa realizada pelo Conselho Federal de Serviço Social no ano de 2005, intitulada: Assistentes Sociais no Brasil: elementos para o estudo do perfil profissional. Serv. Soc. \& Saúde, Campinas, SP v. 14, n. 2 (20), p. 155-178, jul./dez. 2015 ISSN 1676-6806
} 
subalterna da profissão na divisão social e técnica do trabalho [...] limitando o exercício profissional às ações meramente instrumentais” (GUERRA, 2010, p. 97).

Considerando que as condições concretas para o trabalho profissional estão cada vez mais tensionadas pela conjuntura macroeconômica e, consequentemente, pelas alterações no campo da política social, uma questão precisa ser colocada: a formação profissional dos assistentes sociais tem sido orientada para enfrentar criticamente essa realidade e produzir respostas que possam enriquecer a contribuição do Serviço Social para a conquista e efetivação dos direitos sob o ponto de vista da classe trabalhadora?

Cabe ainda questionar se a categoria profissional tem conseguido enfrentar/romper com algumas determinações históricas que compõem a cultura profissional. Estamos falando de uma profissão que traz na sua trajetória um grande descaso pela formação teórico-metodológica rigorosa, como fruto da influência da Igreja Católica na formação profissional.

A resultante é a vigência de uma determinada concepção de teoria,
esta sim, sem correspondência com a prática: teoria como dogma, de
um lado, e teoria que vise a uma mudança imediata, ou teoria de
resultados, de outro”; ainda presenciamos a ideia de que por ser uma
profissão interventiva “[...] sua particularidade está em oferecer
respostas instrumentais, ou seja, que sejam capazes de alterar o
cotidiano dos usuários, e de operar mudanças ainda que paliativas,
imediatas, respostas de caráter reformista-integrador, cujo substrato
teórico são as correntes de base positivistas (estrutural funcionalista,
sistêmica ou holismo)”; profissão muitas vezes “confundida com
vocação, prática de ajuda e/ou militância, de caráter profundamente
idealista, pautada em valores anticapitalistas românticos e
profundamente humanistas cristãos; profissão cuja intervenção se dá
no âmbito da chamada 'questão social', a qual, em muitos momentos é
tratada como questão moral ou problema de administração técnica, e,
atualmente, a questão social volta a ser tratada como ‘caso de
polícia””; [...] 'profissão que tem como espaços sócio-ocupacionais as
políticas sociais, as quais atribuem um determinado ordenamento e
uma determinada configuração à intervenção profissional' (GUERRA,
2011, p. 6 -7).

Nesse caminho, algumas questões precisam ser apontadas na tentativa de explicar como o caldo cultural da profissão se reatualiza e se combina com a expansão da assistencialização ${ }^{8}$, - que reduz a proteção social à assistência social e promove a

\footnotetext{
${ }^{8}$ Cf. MOTA, A. E. Mito da Assistência Social: ensaios sobre Estado, Política e Sociedade. São Paulo: Cortez, 2008.
}

Serv. Soc. \& Saúde, Campinas, SP v.15, n. 2 (22), p. 155-178, jul./dez. 2016 ISSN 1676-6806 
ampliação de programas de combate à miséria, também submetidos às políticas dos organismos internacionais. Ao que parece, esse mesmo processo que tem aumentando as chances dos assistentes sociais se inserirem no mercado de trabalho, contraditoriamente, tem contribuído para o aprofundamento da precarização, que reforça situações de instabilidade, ausência de vínculo, diferentes formas de contratação e baixos salários ${ }^{9}$. Associam-se ainda a institucionalização das chamadas Organizações Sociais (OSs) de caráter “não-governamental”, em alguns casos, executoras terceirizadas da política social formulada pelo Estado, que também estabelecem uma diversidade de vínculos de trabalho, flexibilizando os contratos, a jornada de trabalho e os salários. Tudo isso impulsiona a desqualificação profissional e a fragmentação da categoria.

Behring (2009) ao analisar as condições contemporâneas para o exercício profissional no âmbito da política social irá nos mostrar rebatimentos tanto no que se refere ao espaço físico, quanto no que diz respeito a uma tendência de redefinição do próprio trabalho profissional.

Do ponto de vista físico, há toda sorte de dificuldades, no âmbito da implementação de políticas pobres para os pobres, focalizadas e residuais, considerando o (des)financiamento em curso e a concepção focalista em vigor. Assim, convive-se com salas sem condições de sigilo, móveis antigos, ausência de equipamentos e de condições de registro, falta de manutenção, material de consumo e de investimento em bens de capital e equipamentos. Ao lado disso, tem-se a tendência de redefinição do próprio trabalho profissional, reduzido ao plantão de emergência, à ambulância que tenta salvar as vítimas do ajuste e ao monitoramento da terceirização do trabalho desprofissionalizado, realizado junto aos usuários por ONGs e congêneres (BEHRING, 2009, p. 317).

Entendemos que a intervenção profissional não pode ter como horizonte somente a execução das atividades arroladas nos documentos institucionais, sob o risco de restringir a ação profissional à 'gestão da pobreza' sob a ótica da individualização

\footnotetext{
${ }^{9}$ Dados apresentados pelo Coordenador da Gestão do Trabalho no SUAS (Ministério do Desenvolvimento Social e Combate a Fome) durante o Seminário alusivo ao dia do Assistente Social na cidade de Montes Claros - MG (2013), indicam que os assistentes sociais são os profissionais em maior número atuando no Sistema Único da Assistência Social (aproximadamente 30 mil assistentes sociais trabalhando em CRAS, CREAS e nas gestões municipais). Contudo, dados gerais sobre os trabalhadores do SUAS evidenciam que mais de 50\% destes não possuem vínculo empregatício permanente, o que inclui os assistentes sociais.

Serv. Soc. \& Saúde, Campinas, SP v. 14, n. 2 (20), p. 155-178, jul./dez. 2015 ISSN 1676-6806
} 
das situações sociais e de abordar a questão social a partir de um viés moralizante, entretanto a dinâmica cotidiana, marcada pelo atual movimento do capital e sua interferência no campo da política social, nem sempre garante o tempo necessário para que os profissionais possam estudar e refletir tendo como finalidade desenvolver projetos de coletivização das demandas e organização política dos usuários.

Nesse contexto, as condições concretas para o trabalho profissional estão cada vez mais tensionadas pela ampliação de serviços e demandas, mas sem a correspondente designação de recursos materiais, financeiros e humanos necessários à manutenção da qualidade do que é prestado à população usuária. Isso acaba impactando nas condições [éticas e técnicas] para o exercício profissional, pois as instituições sociais são mediações fundamentais para a participação do Serviço Social no atendimento das demandas incorporadas pelas políticas sociais. Tem-se, portanto, repercussões para as relações de trabalho dos/as assistentes sociais, como também para o exercício de suas atribuições, o que irá repercutir diretamente nos serviços prestados (CFESS, 2012, p. 19).

Assim, se a base de sustentação funcional-ocupacional do assistente social, ou seja, a Política Social, tende a ser significativamente golpeada neste processo, requisitando um profissional que se adapte às exigências do mercado e de suas configurações, identificamos como tendência que a formação profissional seja direcionada para a modelação de um outro perfil profissional diferente daquele sistematizado nas Diretrizes Curriculares de 1996 formuladas pela ABEPSS, que trataremos a seguir.

O que esse redirecionamento pretende é mobilizar profissionais que operam o projeto de gestão da pobreza (e não do seu combate ou erradicação) que vem de cima, que o reitera junto a indivíduos e famílias - para as quais se transfere cada vez mais responsabilidades de reprodução e cujo produto é o acesso 'feliz' a políticas minimalistas e medíocres, a exemplo das políticas de transferência de renda em curso no Brasil que estão a anos luz de propiciar qualquer processo redistributivo, embora tenham impacto imediato importante na vida das populações pobres, propiciando inclusive bases de legitimidade para o projeto em curso (BEHRING, 2009, p. 317).

Diante deste quadro e partindo do pressuposto de que a natureza da educação como tantas outras coisas essenciais nas sociedades contemporâneas - está vinculada ao 
destino do trabalho ${ }^{10}$, a questão a ser problematizada é a produção de profissionais em massa e com conteúdos banalizados.

Reforçamos a hipótese de que colada às atuais requisições da Política Social minimalista e focalizada está a expansão de um projeto de formação profissional que não expressa as Diretrizes Curriculares da ABEPSS de 1996 e que tem como seu maior expoente a graduação a distância.

\section{FORMAÇÃO PROFISSIONAL EM SERVIÇO SOCIAL: TENSÕES ENTRE O PROJETO COLETIVO E A EXPANSÃO DO ENSINO DE GRADUAÇÃO A DISTÂNCIA}

A descoberta do curso de Serviço Social como nicho de valorização relaciona-se a uma demanda do mercado de trabalho, no formato que adquire o enfrentamento das expressões da questão social pelo Estado e as classes na contemporaneidade. Não parece mera coincidência que a expansão da formação profissional em Serviço Social pela via do EaD venha acontecendo concomitante à desqualificação dos padrões de atendimento às expressões da questão social.

A descoberta do curso de Serviço Social como nicho de valorização relaciona-se a uma demanda do mercado de trabalho, no formato que adquire o enfrentamento das expressões da questão social pelo Estado e as classes no neoliberalismo. Trata-se de produzir uma preparação para as requisições de mensuração e gestão/controle dos pobres. Nesse contexto, não se requisita o perfil das diretrizes curriculares [...] Ao contrário, o que se requisita é um profissional à imagem e semelhança da política social focalizada e minimalista de gestão da pobreza [...] (CFESS/CRESS; ABEPSS; ENESSO, 2010, p. 6, grifos nossos).

\footnotetext{
${ }^{10}$ Um sistema que se apoia na separação entre trabalho e capital, que requer a disponibilidade de enorme massa de força de trabalho sem acesso aos meios de sua realização, necessita, ao mesmo tempo, socializar os valores que permitem a sua reprodução. Se no pré-capitalismo a desigualdade era explícita e assumida como tal, no capitalismo - a sociedade mais desigual de toda a história -, para que se aceite 'que todos são iguais perante a lei’ se faz necessário um sistema ideológico que proclame e inculque cotidianamente esses valores na mente das pessoas (MÉSZÁROS, 2009, p. 16).
}

Serv. Soc. \& Saúde, Campinas, SP v. 14, n. 2 (20), p. 155-178, jul./dez. 2015 ISSN 1676-6806 
O debate acerca do crescimento do ensino de graduação a distância no Brasil pode ser localizado a partir do processo histórico que ensejou na contrarreforma do Estado brasileiro e da Política de Educação Superior num cenário marcado pela mundialização do capital e pela reestruturação produtiva. Dessa maneira, o ensino a distância se associará diretamente com a dinâmica atual do capital que necessita expandir seus mercados e, na particularidade brasileira, se adensará a redução do Estado na execução das políticas sociais, ao desfinanciamento, às parcerias público-privada, a medida que impulsionam a privatização no interior das universidades públicas, ao aprofundamento do empresariamento da Educação Superior e à lógica dominante de aligeiramento e massificação da formação. Esses processos atravessaram os governos FHC, bem como os governos petistas (Lula e Dilma), que inclusive diversificaram e consolidaram o Ensino de Graduação a Distância em todo país ${ }^{11}$.

A expansão dessa modalidade de ensino tem se configurado nos últimos anos uma das principais políticas receitadas pelos organismos internacionais, sobretudo o Banco Mundial, a UNESCO e a OMC que inflam em seus documentos o discurso da suposta “democratização do ensino". Nesse caminho Lima (2007) nos alerta que uma reflexão cuidadosa deve demonstrar que o ensino de graduação a distância, pela sua forma e conteúdo, constitui-se “em mais uma estratégia de privatização da educação, configurando-a como um promissor 'mercado educacional', principalmente para os empresários estadunidenses e europeu” (ibid., p. 81).

Se durante o governo FHC, os cursos de $\mathrm{EaD}$ expandiram quase que exclusivamente em relação aos cursos de Pedagogia - sobretudo, para a formação de professores -, a partir de 2006 (governo Lula), o ensino a distância passa a se espraiar para outras áreas, na qual se inclui o curso de Serviço Social. Esse será o cenário que promove a descoberta do curso de Serviço Social pelas grandes empresas do ensino a

\footnotetext{
${ }^{11}$ Nessa modalidade há várias experiências não somente nos cursos superiores ou de especialização, mas também no ensino médio, tecnológico e profissionalizante. No Brasil temos alguns exemplos disso: "Um salto para o futuro" programa concebido, produzido e veiculado pela Fundação Roquete Pinto destinado à atualização de professores; Universidade de Brasília (UnB): experiência de mais de quinze anos em EAD através de cursos de extensão (mais de 50 mil pessoas já se inscreveram), iniciada em 1979, oferecendo mais de 20 cursos, seis dos quais traduzidos da Open University; Centro Federal de Educação Tecnológica (CEFET) do Rio de Janeiro juntamente com a Secretaria de Educação Média e Tecnológica do MEC, um curso de especialização didática aplicada à educação tecnológica; Aeronáutica: através da Universidade da Força Aérea utiliza um programa de EAD para atualização de oficiais; Associação Brasileira de Tecnologia Educacional (ABT): desde a década de 1980, oferece cursos direcionados ao aperfeiçoamento de recursos humanos; Serviço Nacional de Aprendizagem Comercial (SENAC) desde 1976; Fundação Roberto Marinho: Telecurso do $2^{\circ}$ Grau e o Supletivo do $1^{\circ} \mathrm{Grau}$; entre muitos outros. Serv. Soc. \& Saúde, Campinas, SP v.15, n. 2 (22), p. 155-178, jul./dez. 2016 ISSN 1676-6806
} 
distância. Entre os cursos com maior oferta de vagas na modalidade a distância o curso de Serviço Social ocupa o terceiro lugar, perdendo apenas para a Pedagogia e a Administração (INEP, 2011).

Partimos da premissa de que o curso de Serviço Social requer parcos investimentos para a sua criação e manutenção o que certamente despertou o interesse do empresariado e, consequentemente, dos estudantes, já que estes cursos, pelo pouco investimento que requerem, também podem ser oferecidos com mensalidades em valores inferiores no mercado.

Outros dois elementos também podem ser considerados para esta análise, como bem destacam Braz e Rodrigues (2013):

[...] além de ser um curso de natureza interventiva e, portanto, mais apto à formatação de um ensino técnico e meramente instrumental, o Serviço Social tem se apresentado como um artigo de 'venda fácil' uma mercadoria com forte apelo mercantil, porque muito mais barata que os demais cursos de $\mathrm{EaD}$ e, ainda, portadora da capacidade (ilusória) de aumentar, no curto prazo, a 'empregabilidade' dos seus alunos consumidores (BRAZ; RODRIGUES, 2013, p. 274 - 275).

Não obstante, informações levantadas pelo Conselho Federal de Serviço Social (CFESS), Associação Brasileira de Ensino e Pesquisa em Serviço Social (ABEPSS) e Executiva Nacional de Estudantes de Serviço Social (ENESSO) apontam inúmeros problemas relacionados a esses cursos, que têm desrespeitado as legislações e normativas referentes ao Serviço Social brasileiro. Esses dados estão sistematizados e analisados em documento produzido pelas três entidades nomeado "Sobre a Incompatibilidade entre Serviço Social e Graduação a Distância” volumes I e II (2010; 2014).

Os documentos indicam a falta de transparência e dificuldades no acesso aos dados das instituições de ensino; ausência de projetos pedagógicos em consonância com as Diretrizes Curriculares da ABEPSS e do MEC; tutores não assistentes sociais substituindo professores; descumprimento da Lei Federal de Estágio 11.788/2008 e da Resolução CFESS n ${ }^{\circ}$ 533/2008 que disciplina o processo de supervisão direta de estágio em Serviço Social, enquanto atribuição privativa dos assistentes sociais; forte instabilidade institucional e fragilidades administrativas dos polos; ausência da articulação entre ensino, pesquisa e extensão, além de sérias denúncias de assédio moral Serv. Soc. \& Saúde, Campinas, SP v. 14, n. 2 (20), p. 155-178, jul./dez. 2015 ISSN 1676-6806 
junto aos assistentes sociais que se negam a supervisionar os estagiários oriundos de tais cursos (CFESS/CRESS; ABEPSS; ENESSO, 2010).

Considera-se, a partir dos elementos apontados, que o EaD está longe de se constituir em uma alternativa democrática à ampliação do acesso ao Ensino Superior, visto que se apresenta enquanto uma política que reforça as desigualdades sociais e regionais do país; que assegura aos ricos o ensino de qualidade e aos que não possuem condições para acessar as poucas instituições de graduação públicas presenciais ou de custear a sua própria formação de qualidade são ofertados os cursos de EaD - expressão máxima da precarização e da mercantilização da Educação ${ }^{12}$.

Nota-se que ampliação dessa modalidade de graduação tem atendido a contento outros fins, como o atendimento às determinações dos organismos internacionais, onde prevalece a lógica financeira em detrimento da lógica social e a liberalização e internacionalização do comércio, incluindo aí a transmutação da educação de direito em serviço, ou seja, a sua mercantilização. Essa lógica expansionista da educação reflete a perfeita combinação entre os interesses do mercado interno e os interesses políticos governamentais de elevação dos indicadores quantitativos relativos ao Ensino Superior, para atrair novos investimentos para o país e cumprir metas e exigências dos organismos internacionais.

Nessa trilha, ao que tudo indica, está se gestando no Serviço Social brasileiro contemporâneo um assistente social que, reconhecendo equivocadamente a profissão como uma espécie de emergência social, satisfaz-se com uma atuação profissional imediatista e focalista diante das expressões da questão social; um profissional que, operando com destreza os indicadores e técnicas de gerenciamento e monitoramento da pobreza absoluta - quase todos mediados pelas Tecnologias de Informação e Comunicação -, em meio a um caldo de cultura que combina eficácia instrumental, pragmatismo e a velha e reatualizada "intenção" do servir e da ajuda, se apresenta como um agente a serviço do Estado assistencialista e penal (BRAZ; RODRIGUES, 2013).

\footnotetext{
${ }^{12}$ A oferta dos cursos de graduação a distância também está relacionada ao perfil dos estudantes. Os mesmos são direcionados para os trabalhadores e filhos dos trabalhadores da periferia do capitalismo. Informações do Censo da Educação Superior 2011 nos indicam que o "típico aluno" da educação a distância, é do sexo feminino, cursa licenciatura e está vinculado a uma instituição privada. A média de idade dos alunos da graduação a distância nas condições de matrícula, ingresso e concluinte, é de 30 anos (INEP, 2013). Dados do Censo Brasil EaD (2012) confirmam essa informação ao publicar que "os alunos $\mathrm{EaD}$, segundo os respondentes, são, na maioria, integrantes do sexo feminino (51\%), com idade de 18 a 30 anos (50\%), que estudam e trabalham (85\%) (ABED, 2013).

Serv. Soc. \& Saúde, Campinas, SP v.15, n. 2 (22), p. 155-178, jul./dez. 2016 ISSN 1676-6806
} 
Sabe-se que a maior parte das vagas ofertadas para os cursos de Serviço Social tem ocorrido através da graduação a distância ${ }^{13}$. Observamos que a UNOPAR tem sido responsável, sozinha, pela oferta de 21.150 vagas anuais para o curso de Serviço Social. Dados organizados pelo Conselho Federal de Serviço Social (CFESS, 2013) - Tabela 1 - indicam o crescimento do número de bacharéis formados a distância com registro nos Conselhos Regionais de Serviço Social (CRESS) e, consequentemente, devidamente habilitados para o exercício profissional.

O projeto de formação profissional defendido de forma hegemônica pelo Serviço Social brasileiro expressa a visão de homem e de mundo fundada na ontologia do ser social (teoria crítica). Expressa ainda a vinculação do projeto de formação e profissão a um projeto de sociedade (princípio ético fundamental: “opção por um projeto profissional vinculado ao processo de construção de uma nova ordem societária, sem dominação, exploração de classe, etnia e gênero”). Expressa também uma determinada concepção de universidade. Ou seja, uma universidade pública, gratuita, laica, presencial e de qualidade, direcionada aos interesses da coletividade e enraizada na realidade regional e nacional. Direcionada para preservar, no ambiente universitário, a integração entre o ensino, a pesquisa e a extensão e assegurar a liberdade didática, científica e administrativa para produzir e difundir conhecimentos -, e realizar a sua crítica -, voltados aos interesses das maiorias: uma universidade que seja um centro de produção de ciência, de tecnologia, do cultivo das artes e das humanidades; também uma instituição voltada à qualificação de profissionais com alta competência, para além das necessidades do capital e do mercado (IAMAMOTO, 2007).

Assim, o projeto de formação profissional elaborado democrática e coletivamente pela categoria profissional liderada pela então ABESS - Associação Brasileira de Ensino em Serviço Social (1996) -, envolve o comprometimento com uma direção que tenha definido que tipo de profissional se pretende formar; para que formar; para quem formar (ABESS/CEDEPSS, 1996). É um “processo de qualificação teóricometodológico, técnico e ético-político para o exercício dessa especialização do trabalho

\footnotetext{
${ }^{13}$ Dados do INEP/MEC indicam que no ano de 2011 foram ofertadas 68.742 (sessenta e oito mil, setecentas e quarenta e duas) vagas em cursos de Serviço Social na modalidade a distância. No mesmo ano os cursos de modalidade presencial ofertaram apenas 39.290 (trinta e nove mil, duzentas e noventa vagas). Destaca-se que dessas vagas a distância a Universidade do Norte do Paraná (UNOPAR) foi responsável pela oferta de 21.150 (vinte e uma mil, centro e cinquenta) vagas em todo o Brasil. Serv. Soc. \& Saúde, Campinas, SP v. 14, n. 2 (20), p. 155-178, jul./dez. 2015 ISSN 1676-6806
} 
coletivo” (ABESS/CEDEPSS, 1996, p. 163). Possui uma dimensão social potencializada nas atividades de ensino, pesquisa e extensão.

Tabela 1 - Inscrição dos profissionais graduados a distância nos Conselhos Regionais de Serviço Social do Brasil ${ }^{14}$

\begin{tabular}{|c|c|c|c|}
\hline CRESS & $\begin{array}{c}\text { TOTAL } \\
\text { INSCRITOS } \\
\text { ATIVOS } \\
\end{array}$ & $\begin{array}{c}\text { TOTAL } \\
\text { INSCRITOS EAD } \\
\text { ATIVOS }\end{array}$ & $\begin{array}{c}\text { \% INSCRITOS ATIVOS } \\
\text { EAD }\end{array}$ \\
\hline CRESS - $1^{\text {a }}$ Região /PA & - & - & - \\
\hline CRESS - $2^{\mathrm{a}}$ Região /MA & 2825 & 683 & 24,18 \\
\hline CRESS - 3ª Região /CE & 4762 & 926 & 19,44 \\
\hline CRESS - 4 ${ }^{\mathrm{a}}$ Região /PE & 3966 & - & - \\
\hline CRESS - 5a Região /BA & 8666 & 3297 & 38,04 \\
\hline CRESS - $6^{\mathrm{a}}$ Região /MG & 14048 & 2424 & 13,01 \\
\hline CRESS - $7^{\mathrm{a}}$ Região/RJ & 13013 & 498 & 3,83 \\
\hline CRESS - $8^{\mathrm{a}}$ Região/DF & - & - & - \\
\hline CRESS - 9a Região/SP & 28871 & 1598 & 5,53 \\
\hline CRESS - $10^{\mathrm{a}}$ Região/RS & 6111 & - & - \\
\hline CRESS - 11ª Região/PR & 6519 & 333 & 5,11 \\
\hline CRESS - $12^{\mathrm{a}}$ Região/SC & 4200 & 466 & 11,09 \\
\hline CRESS - $13^{\mathrm{a}}$ Região/ PB & 3219 & 286 & 8,88 \\
\hline CRESS - $14^{\mathrm{a}}$ Região/RN & - & - & - \\
\hline CRESS - 15ª Região/AM & 4447 & 675 & 15,18 \\
\hline CRESS - 16a Região/AL & 2889 & 502 & 17,38 \\
\hline CRESS - $17^{\text {a }}$ Região/ES & 4363 & 556 & 12,74 \\
\hline CRESS - 18ª Região/SE & - & - & - \\
\hline CRESS - 19a Região/GO & 2641 & 647 & 24,50 \\
\hline CRESS - 20ª Região/MT & 2460 & 843 & 34,27 \\
\hline CRESS - 21 ${ }^{\mathrm{a}}$ Região/MS & - & - & - \\
\hline CRESS - 22ª Região/PI & 2134 & 373 & 17,48 \\
\hline CRESS - 23ª Região/RO & 2139 & 682 & 31,88 \\
\hline CRESS - 24 Região/AP & 659 & 24 & 3,64 \\
\hline CRESS - 25ª Região/TO & 1234 & 619 & 50,16 \\
\hline TOTAL & 119.166 & 15.432 & 12,95 \\
\hline
\end{tabular}

Fonte: CFESS, 2013

O perfil profissional que se pretende formar, segundo este projeto, é: um profissional capaz de privilegiar a defesa dos direitos sociais, a ampliação da cidadania

\footnotetext{
${ }^{14}$ Observa-se pela Tabela 1 que nem todos os Conselhos Regionais responderam ao levantamento do CFESS, o que indica, certamente, que tanto o número total de inscritos, quanto o número de inscritos ativos oriundos do EaD é ainda maior.
}

Serv. Soc. \& Saúde, Campinas, SP v.15, n. 2 (22), p. 155-178, jul./dez. 2016 ISSN 1676-6806 
e a consolidação da democracia, com uma competência a ser adquirida nas várias dimensões que compõem o agir profissional: teórico-metodológica, técnico-operativa e ético-política.

Nesse sentido, são pressupostos para a formação profissional dos assistentes sociais a compreensão de que:

1) O Serviço Social se particulariza nas relações sociais de produção e reprodução da vida social como uma profissão interventiva no âmbito da questão social, expressa pelas contradições do desenvolvimento do capitalismo monopolista;

2) A relação do Serviço Social com a questão social - fundamento básico da sua existência - é mediatizada por um conjunto de processos sócio-históricos e teóricometodológicos constitutivos de seu processo de trabalho;

3) O agravamento da questão social em face das particularidades do processo de reestruturação produtiva no Brasil, nos marcos da ideologia neoliberal, determina uma inflexão no campo profissional do Serviço Social. Esta inflexão é resultante de novas requisições postas pelo reordenamento do capital e do trabalho, pela "reforma" do Estado e pelo movimento de organização das classes trabalhadoras, com amplas repercussões no mercado profissional de trabalho;

4) Os processos de trabalho, nos quais estão inseridos os assistentes sociais, são determinados pelas configurações estruturais e conjunturais da questão social e pelas formas históricas de seu enfrentamento, permeadas pela ação dos trabalhadores, do capital e do Estado, através das políticas e lutas sociais (ABESS/CEDEPSS, 1996).

Importante ainda ressaltar, sob a luz das Diretrizes, os princípios que orientam os referidos pressupostos da formação profissional: 1) Flexibilidade da organização dos currículos plenos, expressa na possibilidade de definição de disciplinas e/ou outros componentes curriculares - tais como oficinas, seminários temáticos, atividades complementares - como forma de favorecer a dinamicidade do currículo; 2) Rigoroso trato teórico, histórico e metodológico da realidade social e do Serviço Social, que possibilite a compreensão dos problemas e desafios com os quais o profissional se defronta no universo da produção e reprodução da vida social; 3) Adoção de uma teoria social crítica que possibilite a apreensão da totalidade social em suas dimensões de Serv. Soc. \& Saúde, Campinas, SP v. 14, n. 2 (20), p. 155-178, jul./dez. 2015 ISSN 1676-6806 
universalidade, particularidade e singularidade; 4) Superação da fragmentação de conteúdos na organização curricular, evitando-se a dispersão e a pulverização de disciplinas e outros componentes curriculares; 5) Estabelecimento das dimensões investigativa e interventiva como princípios formativos e condição central da formação profissional e da relação entre teoria e realidade; 6) Padrões de desempenho e qualidade idênticos para os cursos diurnos e noturnos, com máximo de quatro horas/aula de atividades nestes últimos; 7) Caráter interdisciplinar nas várias dimensões do projeto de formação profissional; 8) Indissociabilidade nas várias dimensões de ensino, pesquisa e extensão; 9) Exercício do pluralismo como elemento próprio da natureza da vida acadêmica e profissional, impondo-se o necessário debate sobre as várias tendências teóricas, em luta pela direção social da formação profissional, que compõem a produção das Ciências Humanas e Sociais; 10) Ética como princípio formativo perpassando a formação curricular; 11) Indissociabilidade entre estágio e supervisão acadêmica e profissional (ABESS/CEDEPSS, 1996).

Esses elementos nos indicam a grande tensão entre o projeto de formação elaborado coletivamente pela categoria profissional e afinado com o Projeto Ético Político hegemônico na profissão e a expansão acelerada dos cursos de graduação a distância que tem gestado um perfil profissional colaboracionista da ordem estabelecida. Aqui apontamos algumas das tendências que merecem a atenção das entidades organizativas do Serviço Social brasileiro e também dos seus profissionais e estudantes.

\section{CONSIDERAÇÕES FINAIS}

As reflexões e dados apresentados se configuram em resultados que podem indicar que o $\mathrm{EaD}$ no Brasil não possibilita a formação necessária ao profissional de Serviço Social. A materialização do projeto de formação profissional, defendido hegemonicamente pela categoria profissional, não pode ser viabilizada na modalidade EaD, a educação a distância tem distanciado, cada vez mais, a educação do seu caráter formativo e crítico, visto que a formação profissional implica processos pessoais e sociais de relação entre o ensinado e o aprendido e a realidade vivida, no contexto cultural situado, produzindo pessoal e coletivamente a existência social e individual. A riqueza que os ambientes universitários podem proporcionar em termos de socialização 
é difícil de ser reproduzida em ambientes virtuais. O ambiente potencial de convívio e de troca de experiências pessoais e coletivas, do conhecimento tácito, apresenta-se como uma realidade difícil de ser recriada (CFESS/CRESS; ABEPSS; ENESSO, 2010).

As atividades que se referem à formação e ao exercício da profissão se realizam na vida concreta dos sujeitos, na dinâmica da vida social. Esse processo só pode ser construído, compreendido e reformulado na vivência e ação direta entre seus partícipes. Não cabem abstrações ou suposições pré-concebidas em ambientes virtuais para situações emergentes e contraditórias, que tem repercussão direta e rápida na vida dos usuários. Certamente, no ambiente presencial, ainda que com suas limitações, garante-se o direito aos estudantes de orientação responsável para seu futuro exercício pautado no Projeto Ético-Político do Serviço Social, cumprindo as competências e atribuições previstas na Legislação Profissional em vigor (CFESS/CRESS; ABEPSS; ENESSO, 2010).

Não obstante, faz-se necessário aprofundar as pesquisas sobre este tema para que possamos nos aproximar, de forma mais aprofundada, das questões que afetam o exercício e a formação profissional na contemporaneidade.

Faz-se necessário seguir na interpretação marxista do objeto, na tentativa de apanhar dos traços particulares de seu desenvolvimento aquilo que é expressão das leis tendenciais macroscópicas que determinam tais particularidades num dado momento histórico, o que permitirá apanhar os elementos do trabalho e da formação profissional em Serviço Social.

Esse esforço analítico possibilitará buscar os fios capazes de reproduzir, no plano da teoria, o movimento social real do objeto, experimentado empiricamente, no evolver do modo de ser e dos rumos tomados pelo Serviço Social brasileiro.

Recebido em 13.11.2016 - Aprovado em 19.12.2016 


\section{REFERÊNCIAS}

ABED. Censo EaD Brasil: Relatório analítico da aprendizagem a distância no Brasil 2012. Curitiba: IBPEX, 2013.

ABESS/CEDEPSS. Proposta Básica para o Projeto de Formação Profissional. Serviço Social \& Sociedade, n. 50. São Paulo: Cortez, 1996.

ANTUNES, R. Adeus ao trabalho? Ensaios sobre as metamorfoses e a centralidade do mundo do trabalho. 11 ed. São Paulo: Cortez, 2006.

BANCO MUNDIAL. La enseñanza superior: las lecciones derivadas de la experiencia. Washington: Banco Mundial, 1994.

BEHRING, E. Política social no contexto da crise capitalista. In: Serviço Social: direitos e competências profissionais. Brasília: CFESS/ABEPSS, 2009.

BEHRING, E. R.; BOSCHETTI, I. Política Social: fundamentos e história. 2 ed. São Paulo: Cortez, 2007.

BRAZ, M; RODRIGUES, M. O ensino em Serviço Social da era neoliberal (1990 2010): avanços, retrocessos e enormes desafios. In: SILVA, J. F. S; SANT’ANA, R. S; LOURENÇO, E. A. S. (Orgs.). Sociabilidade burguesa e Serviço Social. 1 ed. Rio de Janeiro: Lumen Juris, 2013.

CFESS. Atribuições privativas do/a assistente social em questão. 1ed ampliada. Brasília: CFESS, 2012.

CFESS/CRESS; ABEPSS; ENESSO. Sobre a incompatibilidade entre graduação à distância e Serviço Social. Brasília: CFESS, 2010.

CFESS/CRESS; ABEPSS; ENESSO. Sobre a incompatibilidade entre graduação a distância e Serviço Social. v. 2. Brasília: CFESS, 2014.

GUERRA, Y. Serviço Social: dilemas da precarização e estratégias de enfrentamento. In: COSTA, G. M.; PRÉDES, R.; SOUZA, R. (Orgs.). Crise contemporânea e Serviço Social. Maceió: EDUFAL, 2010.

GUERRA, Y. O Projeto Ético Político do Serviço Social brasileiro frente às demandas do ensino superior. In: Anais... IV Simpósio Regional de Formação Profissional e XIX Semana Acadêmica de Serviço Social. Universidade Estadual do Oeste do Paraná (UNOESTE - Campus Toledo), 27 a 29 de julho de 2011.

HARVEY, D. A condição pós-moderna. São Paulo: Editora Loyola, 1992. 
HORODYNSKI, M. L. Ensino a distância e Universidade Aberta do Brasil: mitos a serem desfeitos. São Paulo: APROPUC, 2010.

IAMAMOTO, M. V. Serviço Social em tempo de capital fetiche: capital financeiro, trabalho e questão social. 2 ed. São Paulo: Cortez, 2007.

IAMAMOTO, M. V. Projeto profissional, espaços ocupacionais e trabalho do assistente social na atualidade. In: CFESS. Atribuições privativas do/a assistente social em questão. 1ed ampliada. Brasília: CFESS, 2012.

INEP/MEC. Sinopse Estatística da Educação Superior: graduação, 2011. Disponível em: <http://portal.inep.gov.br/superior-censosuperior-sinopse>. Acessado em: 20 set. 2013.

INEP/MEC. Resumo técnico: Censo da Educação Superior 2011. Brasília: INEP/MEC, 2013.

LIMA, K. Contrarreforma na Educação Superior: de FHC a Lula. São Paulo: Xamã, 2007

MÉSZAROS, I. A crise estrutural do capital. São Paulo: Boitempo, 2009.

NETTO, J. P. Transformações societárias e Serviço Social: notas para uma análise prospectiva da profissão. Serviço Social \& Sociedade, ano XVII, n 50. São Paulo: Cortez, 1996. 